\title{
CRENÇAS E A FORMAÇÃO DOCENTE: CONSIDERAÇÕES SOBRE O ENSINO E APRENDIZAGEM DE LÍNGUA ESTRANGEIRA
}

\author{
BEILIEFS AND INITIALNTEACHER EDUCATION: CONSIDERATIONS ON \\ FOREIGN LANGUAGE TEACHING AND LEARNING
}

\section{LES CROYANCES ET LA FORMATION DES MAÎTRES : RÉFLÉXIONS SUR L'ENSEIGNEMENT ET APPRENTISSAGE DE LANGUE ÉTRANGÈRE}

\author{
Simone Makiyama \\ Mestre e Doutora em Linguística, professora do curso de Letras-inglês na Universidade \\ Federal de Alagoas, com projetos relacionados à formação de professores, ensino e \\ aprendizagem de línguas e estudos do discurso. \\ E-mail: simone.makiyama@fale.ufal.br
}

\section{Rosária Cristina Costa Ribeiro}

Mestre e Doutora em Estudos Literários, professora do Curso de Letras Francês na Universidade Federal de Alagoas. Vice-líder do Grupo de Pesquisa de Aprendizagem da Língua e Literaturas Francesas - GEFALL (Universidade Federal de Pernambuco).

E-mail: rosaria.ribeiro@fale.ufal.br

\section{RESUMO}

Este trabalho apresenta os resultados de uma pesquisa conduzida com licenciandos de Letras com habilitação em língua inglesa, espanhola, francesa, e que teve por finalidade investigar suas crenças sobre como aprender (e ensinar) essa língua de forma satisfatória, cujas informações foram coletadas por meio de questionário. A partir da teoria sociocultural de Vygotsky e dos estudos empreendidos por Barcelos, a análise desse material permitiu verificar que crenças em relação a autonomia, como a autoinstrução e o contato com nativos, refletem-se nas escolhas de estratégias de aprendizagem. A contribuição deste estudo se dá ao depreender em que medida as experiências enquanto aprendizes de língua estrangeira desses novos professores podem influenciar a sua forma de ensinar, bem como o papel do curso de Letras no processo de percepção de crenças para que futuros docentes possam questioná-las e, dessa forma, se viabilize um fazer pedagógico mais consciente a fim de que eles se tornem verdadeiros agentes na promoção de mudanças significativas na educação.

Palavras-chave: Formação inicial de professores - Ensino de Língua Estrangeira - Crenças da aprendizagem.

\section{ABSTRACT}

This article presents the results of a research involving Letters undergraduate students of English, Spanish and French language. This study aims at investigating their beliefs on how to learn (and teach) foreign languages successfully and the data for this inquiry was collected through questionnaires. Based on Vygotsky's sociocultural theory and Barcelos's studies, the analysis of this material enables to ascertain that beliefs related to autonomy, such as the need for self-instruction and contact with native speakers, reflect upon their choices for learning strategies. The contribution of this study relies on to what extent their experience as foreign 
language learners can influence their practice as future teachers as well as the role of Letters course in the awareness process of their own beliefs so as to promote more reflective teaching practice in order to become genuine agents to bring about significant change in the educational field.

Keywords: Initial teacher education - Foreign language teaching - Learning beliefs.

\section{RÉSUMÉ}

Cet article présente les résultats d'une enquête menée auprès des étudiants du cours de Lettres en langues étrangères, anglais, français et espagnol, et qui a eu pour but étudier leurs croyances sur l'enseignement (et l'apprentissage) une langue de façon satisfaisante, exprimées par un questionnaire. À partir de la théorie socioculturelle de Vygotsky et les études développées par Barcelos, l'analyse du matériel qui nous a pemis de vérifier que les croyances par rapport à l'autonomie, tant que l'auto-instruction et le contact avec les natifs, se reflètent dans leurs choix méthodologiques. La contribution de cette étude se donne dans la mesure que montre comment les expériences de ces apprentis ont des influences sur les nouveaux maîtres en formation, et aussi le rôle de la formation dans le procès de perception de ces croyances pour que les futurs maîtres puissent les mettre en examen, et, de cette façon, elles puissent conduire à une praxis plus consciente, et que ces étudiants puissent être les agents de modification dans leur entourage scolaire.

Mots-clé: Formation Initiale des Maîtres - Enseignement de langues étrangères - Croyances de l'apprentissage.

\section{INTRODUÇÃO}

Muitas pesquisas na área de estudo de línguas com enfoque nas crenças sobre a aprendizagem têm surgido (KAJALA, 1995, KUDIESS, 2005, BARCELOS, 2007, SILVA, 2011, LIMA; PIRES, 2014), desvelando a relevância desse escopo na prática pedagógica. Isso pode ser decorrência do fato de que a forma como se concebe o processo de ensinar e aprender pode determinar o modo de agir tanto de professores quanto de aprendizes nesse percurso. Assim, o presente artigo apresenta um recorte de uma pesquisa que tem como objetivo investigar as crenças de licenciandos de Letras sobre aprender línguas estrangeiras de forma satisfatória, vislumbrando possíveis implicações na prática desses futuros professores. Para a investigação deste trabalho, foram elaboradas as seguintes perguntas norteadoras:

1) como as crenças em relação à aprendizagem de línguas são percebidas entre os alunos-sujeitos da pesquisa?

2) como essas crenças direcionam o fazer desses alunos em relação à aprendizagem de línguas estrangeiras?

Com este estudo, buscamos contribuir para os trabalhos referentes ao processo de ensino e aprendizagem de línguas bem como colaborar com informações para a reflexão no que diz respeito à formação de professores em pré-serviço. Para isso, traçamos um breve 
percurso teórico que tem como ponto de partida os estudos sobre a teoria sociocultural de Vygotzky (2008), passando pela reflexão de alguns conceitos basilares para este estudo, como os de autonomia, autoinstrução e crenças, e, finalizamos apresentando uma breve a análise e considerações sobre dados recolhidos junto a um grupo de alunos do curso de Letras.

\section{DESENVOLVIMENTO}

\section{Processo de aprendizagem}

Este trabalho adota a teoria sociocultural de aprendizagem de Vygotsky, que entende o processo de aprendizagem como resultado das interações sociais mediadas por elementos socioculturais, dentre os quais a linguagem tem papel relevante (VYGOSTSKY, 2008). É por meio da linguagem que se estabelece a relação entre a interação interpessoal (social) e a interação intrapessoal (cognitiva) promovendo, desta forma, a aprendizagem. Para ilustrar este processo, Vygotsky elabora a Zona de Desenvolvimento Proximal (ZPD) que, em linhas gerais, corresponde ao lugar metafórico em que o aprendiz lida com uma tarefa que, inicialmente, só pode ser realizada com o apoio do outro. Após uma fase de assimilação e uso do novo conhecimento, o aprendiz passaria a realizá-la de maneira independente, demonstrando, assim, que o conhecimento sendo construído socialmente, resultado dessa relação de interações sociais e cognitivas.

Seguindo essa perspectiva, este estudo entende a formação de crenças também como resultado dessas interações que os sujeitos estabelecem ao longo da vida e que os levam a determinadas formas de pensar e agir. Levando essa premissa à sala de aula, investigar as crenças de aprendizagem que permeiam este contexto se torna fundamental, uma vez que elas têm uma grande influência na forma como professores e alunos se veem no processo de ensino e aprendizagem e em suas atitudes, tendo, consequentemente, um impacto significativo no resultado final. Essa condição pode ter levado Almeida Filho (1993) e Kumaravadivelu (1998) a afirmarem que desencontros nas crenças de professores e alunos podem causar dificuldades no aprendizado, pois podem gerar um sentimento de frustração para ambas as partes, favorecendo a consolidação de crenças que prejudicam a aprendizagem. Por esta razão, trabalhar a conscientização das crenças ainda na formação inicial de professores é essencial para que haja uma melhor compreensão de seu fazer pedagógico e dos resultados obtidos em sala de aula. 


\section{Crenças e o processo de aprendizagem}

O conceito de crenças não é exclusivo do âmbito educacional. Como afirma Barcelos (2004), esse termo é empregado em uma variedade de áreas de conhecimento. Essa variedade também se apresenta na terminologia empregada no âmbito da aprendizagem de línguas estrangeiras. Silva (2011) faz um levantamento de alguns termos adotados por diferentes pesquisadores, como "cultura de aprender" elaborado por Almeida Filho (1993), "imaginário" empregado por Cardoso (2002) e "representações" adotado por Magalhães (2004). Brown (2001) também utiliza a expressão "abordagem” para se referir às crenças que professores têm em relação a como promover uma boa aprendizagem de línguas. A despeito dos diferentes termos, todos resultam das interações de preconcepções dos sujeitos, frutos de suas experiências. Assim como Woods (2003), acreditamos que, mais do que definir a escolha do termo, é importante delinear o que o conceito envolve. Neste estudo, nos fundamentamos em Barcelos (2007), que descreve crenças como construtos da realidade constituídos sóciohistoricamente, decorrentes de processos interacionais de (re)significação. Em outras palavras, há um processo de interpretação da realidade ancorada nas práticas sociais, em que o sujeito atribui sentidos ao mundo social devido à sua natureza simbólica. Dentre suas características, as crenças se destacam por seu aspecto social (mas também individual), dinâmico (pois podem mudar ao longo das várias vivências dos sujeitos), contextual (por emergirem no contexto da interação) e paradoxal (uma vez que compreendem uma relação entre o social e o individual, as crenças podem ser contraditórias).

Barcelos (2004) nos informa que estudos com o enfoque nas crenças sobre a aprendizagem começaram em meados dos anos 1980 e muitos destes trabalhos se baseiam em um instrumento elaborado por Horwitz (1999) denominado Inventário de Crenças sobre Aprendizagem de Línguas (BALLI, do inglês Beliefs about Language Learning Inventory). Sua intenção era contemplar as crenças mais comuns que aprendizes de línguas apresentavam de forma sistemática. Assim, BALLI elenca cinco categorias principais, fundamentadas em características comuns: 1) crenças sobre o nível de dificuldade que a língua em estudo apresenta; 2) crenças sobre aptidão individual para a aprendizagem; 3) crenças sobre o processo de aprendizagem de línguas; 4) crenças sobre motivação e expectativas e 5) crenças sobre comunicação. Como podemos observar, este instrumento era limitado, mas foi muito útil como ponto de partida para várias investigações com este escopo. Em seus estudos, a própria autora conclui que o inventário não dá conta de abarcar todas as crenças de 
aprendizagem e, em trabalhos posteriores, ela sugere que o inventário seja usado para comparar crenças entre aprendizes (op. cit., 1999).

Algumas pesquisas abrangem a relação entre crenças de aprendizagem e vários aspectos do processo de ensinar e aprender. Makiyama (2008), por exemplo, investigou a relação entre as crenças e o uso de estratégias de aprendizagem de um professor de inglês e seus alunos e descobriu que nem sempre esta relação é congruente devido ao atravessamento de várias formações discursivas no dizer e fazer desses sujeitos. Já Carraro e Natel (2011) pesquisaram as crenças sobre o ensino de gramática de professores de espanhol e chegaram à conclusão que a origem de suas crenças derivam tanto de sua experiência como aprendizes quanto de sua formação profissional, além da influência do material didático adotado. Monti (2012), por seu turno, ao investigar as crenças de licenciandos de Letras acerca do que é ser um bom professor, constatou que ele é resultado de uma combinação de uma formação de curso de idiomas com programas de intercâmbio, depreendendo uma visão que prioriza a competência linguístico-comunicativa na formação docente.

Levando em consideração a relevância da conscientização das crenças na formação inicial devido à sua influência no processo de ensino e aprendizagem, este estudo buscou investigar quais as crenças que licenciandos de Letras têm em relação a como aprender uma língua estrangeira. A tomada de consciência de suas próprias crenças pode viabilizar uma reflexão mais crítica no que concerne às crenças, assim como a percepção de que não existem crenças "certas ou erradas", já que são resultado de experiências ocorridas em processos interativos e que podem explicar determinadas atitudes no modo de aprender e ensinar.

\section{Metodologia}

Em 2016, tem início um projeto que objetiva investigar junto a um grupo de licenciandos em Letras, com habilitação em língua inglesa, francesa espanhol e portuguesa, suas crenças e as possíveis implicações desta na sua práxis. Ressaltamos aqui que, para este trabalho, apresentamos somente um recorte do projeto, com foco na elaboração dos questionários, pelos membros do projeto, e nas respostas dos alunos-instrutores, afim de investigar como esses licenciandos compreendem as crenças e as estratégias que delas derivam.

O projeto foi composto por dois grupos de licenciandos do curso de Letras da Universidade Federal de Alagoas (UFAL), de diversas habilitações e períodos. Constituído por sete membros, o primeiro grupo elaborou questionários, aplicou e analisou os resultados 
obtidos por meio desses instrumentos, sob a orientação de um professor-pesquisador. Esse grupo desenvolveu discussões que abordaram o ensino de língua estrangeira, mesclando alguns conceitos e pontos de vista das disciplinas de Política da Educação Básica no Brasil e de Linguística Aplicada ao Ensino de Línguas. Já o segundo grupo contou com três alunosinstrutores, licenciandos do curso de Letras, integrantes de um projeto de extensão universitária que desenvolve o ensino e o aprendizado de línguas estrangeiras no seio da mesma instituição. Os resultados apresentados neste artigo se baseiam no questionário direcionado aos professores-instrutores, suas crenças em relação ao ensino de línguas estrangeiras, e como essas crenças influenciam em suas atitudes e escolhas em sala de aula.

Assim, no âmbito do projeto relatado, durante as discussões realizadas pelo primeiro grupo, foram debatidos conceitos relacionados à questão da autonomia, com base nas ideias de Paulo Freire (1996), de H. Holec (1990), e sobre crenças (BARCELOS, 2001, FÉLIX, 2007). A partir dessas discussões, os membros do projeto despertaram sua atenção para as crenças que existem em torno do processo de ensino e aprendizagem de línguas estrangeiras. Após algumas leituras sobre as diversas metodologias científicas que estavam presentes nas investigações sobre as crenças dos professores, em formação inicial ou em serviço, optou-se por desenvolver uma breve pesquisa, de cunho normativo, em que foi desenvolvido um questionário fechado voltado para os professores em formação. Os professores-instrutores, presentes no segundo grupo, foram escolhidos por serem colegas de curso dos membros do projeto, mas não participaram da elaboração do questionário nem das discussões. Como já exposto anteriormente, esses professores em formação inicial lecionam diferentes línguas (inglês, espanhol e francês) em um programa de extensão, desenvolvido dentro da UFAL, voltado para o ensino/aprendizagem de língua estrangeira e ofertado para a comunidade acadêmica.

Para a elaboração do questionário, priorizou-se a descrição das crenças e o seu papel na aquisição de uma língua estrangeira. Para fundamentar a investigação, foi realizado um breve levantamento das metodologias comumente utilizadas. Dessa forma, chegamos às seguintes possibilidades: segundo Barcelos (2001), existem três abordagens metodológicas para se tratar das crenças, a saber, a normativa, a metacognitiva e a contextual.

A primeira abordagem, chamada de abordagem normativa, infere as crenças através de um conjunto pré-determinado de afirmações. A segunda abordagem, metacognitiva, utiliza auto-relatos e entrevistas para inferir as crenças sobre aprendizagem de línguas. A terceira abordagem, contextuai, usa 
ferramentas etnográficas e entrevistas para investigar as crenças através de afirmações e ações. (B ARCELOS, 2001, p. 75)

Assim, devido ao pouco tempo disponível e ao intuito de investigar não somente os três alunos-instrutores envolvidos, mas também a visão de crenças dos licenciandos do primeiro grupo no processo de elaboração do questionário e os próprios alunos desses professores-instrutores, nesse momento optamos por realizar uma investigação de cunho normativo. Dessa forma, apesar das limitações que este tipo de abordagem apresenta, pudemos verificar alguns resultados importantes sobre influência das crenças desses sujeitos que se mostrou voltada para a escolha de estratégias de aprendizagem.

No que diz respeito aos procedimentos metodológicos, é importante enfatizar que esse tipo de abordagem prioriza a utilização de questionários do tipo Likert-scale, como se pode conferir no questionário em anexo. "Esse tipo de questionário contém afirmações com alternativas que vão desde "eu concordo inteiramente" até "eu discordo inteiramente". O questionário empregado por nós foi desenvolvido com base no questionário CRESAL (Crenças Sobre Aprendizagem de Línguas), versão em português do já citado questionário BALLI de Horwitz (1999) e no questionário proposto por Oxford (1990) acerca de estratégias de aprendizagem, uma vez que percebeu-se a necessidade que incluir este elemento na formulação do questionário deste estudo.

Vale ressaltar que o processo de concepção do questionário aconteceu coletivamente e contou com a participação efetiva e ativa dos membros do projeto, com base nas discussões e na sua própria experiência de aprendiz de língua estrangeira (vide Anexo). Ou seja, esse questionário, baseado em crenças e estratégias para o ensino e aprendizado de línguas estrangeiras e voltado para licenciandos do curso de Letras, também foi construído por alunos desse mesmo curso. Assim, é possível analisar as próprias escolhas dos membros do primeiro grupo e inferir sobre suas crenças. Quando observadas mais atentamente, percebemos que o questionário elaborado por eles tem como base questões que mostram uma visão mais conservadora do processo de ensino e aprendizagem. Outro ponto interessante é a predominância de questões voltadas para a oralidade, o que vem ao encontro da crença de que o aluno com êxito é aquele que aprende a falar a língua, deixando as competências de compreensão e produção escritas em segundo plano ou até mesmo apagadas. Essa questão também já foi explorada por PAIVA (2009), em um artigo em que a pesquisadora analisa as narrativas de aprendizagem de um grupo de participantes de um projeto e enfatiza exatamente a importância que os alunos atribuem, principalmente no aprendizado de língua inglesa, ao 
interesse pela oralidade, voltada, sobretudo, para cultura de massa (música, cinema e televisão). Por outro lado, não podemos nos esquecer de que essa ênfase na oralidade também pode ser vista como decorrente da abordagem comunicativa, que valoriza em seus estágios iniciais, situações de comunicação que envolvem a oralidade (MAKIYAMA, 2015).

No que diz respeito à aplicação do questionário, cada aluno-instrutor foi acompanhado por membro do projeto. Para que pudéssemos garantir a fidedignidade das informações coletadas, optamos pelo anonimato dos participantes no preenchimento do questionário.

\section{Análise das crenças}

A partir da discussão das crenças enumeradas pelos membros do projeto, nosso questionário concentra-se em questões referentes tanto às crenças quanto à escolha de estratégias de aprendizagem para poder fazer considerações sobre a relação entre estes dois elementos. As crenças selecionadas giram em torno da busca por maneiras mais eficazes de se aprender uma língua estrangeira e quais as estratégias podem derivar dessas crenças. Três crenças de aprendizagem de aparecem de forma mais recorrente, a saber: relevância da autoinstrução do aluno, necessidade de contato com falantes nativos e a preponderância do conhecimento da língua estrangeira para fins acadêmico-profissionais.

No que diz respeito à composição e formatação do questionário, este apresenta duas partes distintas, mas complementares. A primeira, totalmente baseada no trabalho de Oxford (1990), foi traduzida diretamente das 130 questões propostas pela pesquisadora e adaptadas ao contexto de pesquisa, uma vez que, no original, o questionário referia-se somente ao ensino e aprendizagem da língua inglesa. Já a segunda parte, foi desenvolvida pelos alunos como uma forma de complementar perguntas iniciais. Dessa forma, a segunda parte do questionário representa uma retomada de algumas ideias presentes no primeiro quadro.

Para este artigo, selecionamos algumas das questões que concentram-se nas três crenças identificadas e nas estratégias que delas derivam. A seguir, discorreremos sobre essas crenças mais detidamente.

\section{A relevância da autoinstrução do aluno}

De acordo com a análise dos questionários, observamos que os entrevistados acreditam na relevância da autoinstrução do aluno, ou seja, ele deve buscar maneiras para desenvolver sua competência na língua de forma independente. Nesse sentido, os sujeitos desta pesquisa apontam estratégias para promover sua autoinstrução, como, por exemplo, 
conhecer bem seus objetivos, reconhecer os tipos de atividades que contribuem para alcançar esses objetivos, a consciência da responsabilidade por seu progresso e a auto avaliação. Segue um gráfico que apresenta o resultado de uma das questões que tratam diretamente sobre essa crença:

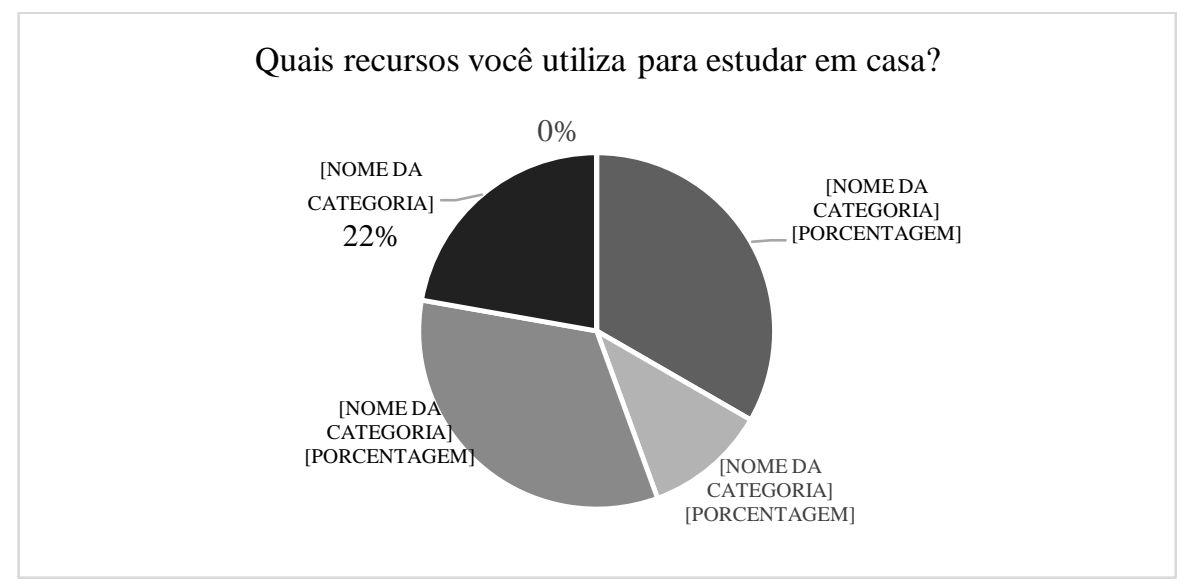

Como já discutido anteriormente, por tratar-se de questionário desenvolvido pelos membros do projeto e que também são alunos do curso de Letras, constatamos que as escolhas de estratégias feitas por eles apresentam cunho mais tradicional, o que pode indicar a visão conservadora do processo de ensino e aprendizagem, depreendendo a possibilidade de reprodução dessas atividades no fazer pedagógico desses futuros professores, tanto daqueles que elaboraram o questionário quanto dos entrevistados, haja vista que eles também escolheram tais estratégias ao responder ao questionário.

No que diz respeito diretamente à autoinstrução como elemento para a autonomia do aprendiz, a análise deste estudo constatou um conflito entre o papel do professor como uma gente facilitador, característico do universo dos cursos livres e do professor como detentor do saber, presente no ambiente do ensino regular. Isso pode levar a uma "autonomia" contraditória do aluno em esperar que o professor diga o que ele deve fazer para buscar a autoinstrução. É o que mostram também os dados referentes à questão "Quais recursos você utiliza para estudar em casa?". Mesmo em se tratando de alunos-instrutores, ou seja, licenciandos que também já atuam em sala de aula, a figura do professor é ainda vista como central no processo de aprender. Ainda que a autoinstrução implique a reponsabilidade do aluno pela aprendizagem, o professor carrega o prognóstico sobre o êxito ou o fracasso do aprendiz. Em outras palavras, é necessária a figura do professor para que a autoinstrução ocorra. 


\section{Necessidade de contato com falantes nativos}

A segunda crença identificada neste estudo indica um fator que todos os participantes da pesquisa apontam como primordial para o êxito na aprendizagem de línguas mais enraizadas nos cursos de Letras, mas também nos cursos livres de idiomas: a participação de programas de imersão. Ou seja, é necessário estar em um ambiente em que a língua em estudo seja a língua corrente para que se possa ter contato com falantes nativos e, desse modo, potencializar seu aprendizado ao ter a chance de suprir todas as deficiências linguísticas acumuladas durante seus anos de estudo. De fato, a imersão pode surtir bons efeitos no que se refere ao aprendizado, sobremaneira, ao que concerne à culturalidade.

É interessante perceber que, se esse contato não for realizado em situações de imersão, os sujeitos dessa pesquisa evitam se expor linguisticamente com um falante nativo, mesmo sabendo que essa exposição pode ser enriquecedora para ele. Mesmo tratando-se de alunos de um curso de licenciatura e que são estimulados a desenvolverem tanto competências linguísticas quanto didático-pedagógicas, percebemos que o risco de errar os impedem de buscar situações que possibilitem o contato com falantes nativos. Tal condição pode ser decorrência da experiência vivenciada no contexto escolar regular, em que o processo avaliativo é baseado em acertos e erros. Outrossim, considerando a crença de que o docente é o detentor do saber, o contato com falantes nativos por professores em formação inicial pode gerar um sentimento de insegurança no uso da língua estrangeira, uma vez que o nativo é tido como o falante ideal, crença que pode explicar a preferência de muitos por "professores nativos", ainda que eles não tenham uma qualificação docente. Ainda que seja essencial, sabemos que a competência linguística compõe um dos elementos necessários para um bom professor de línguas. Sem uma formação didático-pedagógica, o professor não consegue sair do nível da intuição para entender o que envolve o processo de ensinar e aprender.

Eu procuro por pessoas com quem eu possa falar em língua estrangeira

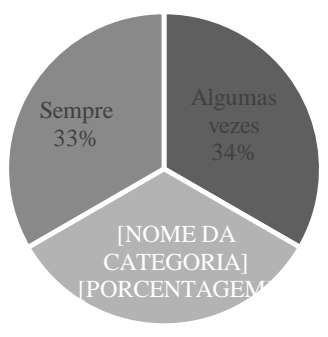


Eu peço ajuda a falantes de língua estrangeira

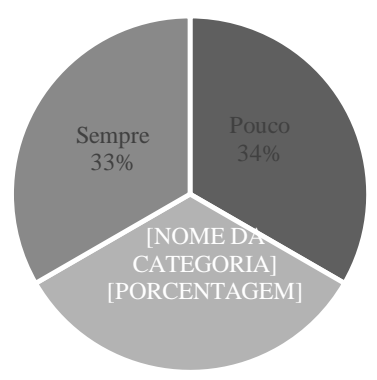

Outra questão importante quando se considera o contato com o falante nativo é a mobilidade identitária. Segundo Woodward (2000), uma das perspectivas de organização da identidade é a essencialista. Essa perspectiva aborda o deslocamento do indivíduo tanto de seu lugar no mundo social e cultural quanto de si próprio, ou seja, tudo aquilo que ele conhece como sua própria existência. Por esta razão, a língua tem um caráter estruturante na subjetividade, que o constitui enquanto sujeito falante daquela comunidade linguística (SERRANI-INFANTE, 2003). Portanto, o encontro com a língua do outro sempre causa perturbação. Quando confrontado com o diferente, nascem um sentimento de perda e uma crise de identidade. Assim, perante o outro, o nativo, o aluno-instrutor tem sua identidade reelaborada a partir de um novo ponto de vista, um novo lugar. Além disso, há a crença de que o bom professor de línguas é linguisticamente competente, cuja imagem professores em formação inevitavelmente buscam se identificar, articulado com a crença de que o bom professor não erra. Como resultado, o contato com nativos, embora valorizado, não é efetivamente buscado e, interpretado, muitas vezes, como timidez e que é vista no processo de aprendizagem de línguas como entrave na aprendizagem de línguas (MAKIYAMA, 2015), cuja origem se encontra nas abordagens de ensino de cunho comunicativo, bastante corrente no domínio dos cursos de línguas. Como podemos observar, devido à complexidade que envolve a aprendizagem de línguas, a insegurança do aluno-instrutor ao se expressar na língua em estudo pode desvelar o movimento identitário que ocorre no contato com o falante nativo.

\section{A preponderância do conhecimento da língua estrangeira para fins acadêmico-} profissionais.

Por fim, a última crença que identificada neste estudo trata-se da importância da língua estrangeira para o desenvolvimento acadêmico e/ou. Por tratar-se de um contexto 
universitário, os membros do grupo levantaram a crença de que esse ambiente favoreceria o aprimoramento da competência de compreensão escrita e o domínio dos gêneros textuais presentes no universo acadêmico.

Eu busco por oportunidades para ler em língua estrangeira?

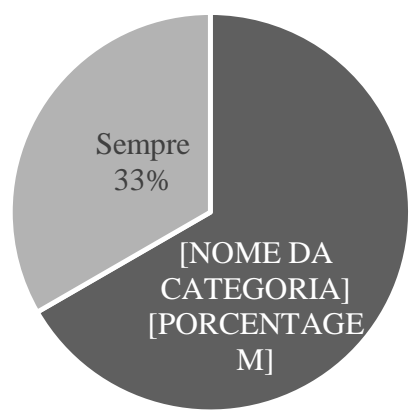

Durante o processo de análise, observou-se que as estratégias que visavam o desenvolvimento desses aspectos se mostraram muito expressivos no material levantado pelos questionários. Aqui, podemos inferir que o contexto da extensão universitária, voltada, como dito anteriormente, para a comunidade acadêmica, pode justificar a proeminência desse propósito do estudo de línguas. Segundo Brown (2001), esse é um dos fatores que orientam os alunos a se dedicar ao aprendizado. Diferentemente das anteriores, essa crença não se refere ao aprendizado como um fim em si mesmo, mas como um instrumento necessário para alcançar outros objetivos.

\section{ALGUMAS CONSIDERAÇÕES À GUISA DE CONCLUSÃO}

Ao fazer um balanço dos aspectos levantados e das análises realizadas, uma das primeiras considerações que nos parece pertinente fazer é em relação à escolha metodológica. Uma das vantagens mais perceptíveis da escolha por trabalhar com um questionário fechado, seguindo uma metodologia de cunho normativo é principalmente a questão da praticidade que ela representa. Se os pesquisadores têm pouco tempo para o processo de análise de informações ou precisam lidar com grandes quantidades de dados, este acaba sendo o modelo de mais conveniente. Além disso, este tipo de questionário também permite observar como uma determinada crença evolui ao longo do tempo, uma vez que ele permite ser aplicado a diferentes turmas, em diferentes momentos.

Por outro lado, por tratar-se de um questionário fechado, com respostas préestabelecidas, os entrevistados ficam restritos às questões e às opções apresentadas, não 
podendo se expressar outros aspectos que não estejam contemplados no questionário. A complementação feita ao questionário inicial se mostrou falha, pois não nos permitiu ter uma visão mais ampla e detalhada dos entrevistados. Esse fato se dá também pela dificuldade que este tipo de instrumento apresenta para empreender uma análise mais aprofundada do contexto onde os alunos agiam e interagiam. Nesse sentido, ainda que limitado, esse tipo de abordagem pode auxiliar em fases iniciais de levantamento de informações para dar direcionamento às próximas etapas da pesquisa.

Outro aspecto importante a se considerar nesta conclusão é a questão da autonomia, muito presente nos contextos de ensino/aprendizagem de língua estrangeira, nos dias atuais. Esse tema, que já fazia parte das discussões surgidas dentro das universidades e círculos acadêmicos desde a década de 1970, com o aparecimento da abordagem comunicativa, ganhou força com a publicação do Quadro Comum Europeu de Referência para o ensino de línguas (2001). Essa publicação do Conselho Europeu acabou por transformar-se em um texto de referência para os mais diversos contextos fora desse continente, inclusive em nosso país. No Quadro, a autonomia tem relação direta com o contexto plurilíngue e o hábito de aprender diversas línguas estrangeiras ao longo da vida, contexto muito diferente do brasileiro, por exemplo. A influência desse entendimento pode ser explicada pelo fato de que os materiais didáticos produzidos para o ensino de línguas são, de maneira geral, feitos na Europa. No contexto brasileiro, no entanto, a construção dessa autonomia se confunde com o conceito de autoinstrução orientada pelo professor, como vimos na análise do material deste trabalho. Isso pode ser reflexo de um posicionamento de como a autonomia era vista no âmbito educacional. Segundo Paiva (2006), durante muito tempo, a autonomia foi algo a se evitar. O controle exercido pelos professores sobre os alunos, e dos métodos sobre os professores, que naquele momento realmente concentravam demasiadamente o processo de ensino e aprendizagem em suas mãos, não permitia ao aluno refletir sobre o processo pelo qual ele passava e pelo qual ele também deveria ser responsável. Um exemplo inspirado em uma narrativa de aprendizagem da própria autora relaciona-se ao uso da metodologia audiovisual, que controlava de forma absoluta o conteúdo ao qual o aprendiz tinha acesso, e acreditava que quanto maior o controle exercido pelo professor, maior as chances de êxito. Nesse mesmo artigo, Paiva revisita diversos conceitos de autonomia, chegando até mesmo aos nossos dias em que autonomia está também ligada ao domínio dos meios ligados à tecnologia da informação. Assim, ela chega à seguinte lista, apesar de considerar que essas diversas definições são falhas por não considerarem as dificuldades do desenvolvimento da autonomia: 
Resumindo, podemos dizer que os conceitos de autonomia focam um ou mais dos seguintes pontos:

- Capacidade inata

- Um conjunto de habilidades que podem ser aprendidas (Benson, 1997)

- Responsabilidade sobre a própria aprendizagem

- Controle sobre o conteúdo e o processo, auto-direção, auto-gerenciamento

- Direito/liberdade para fazer suas próprias escolhas e para construir a própria aprendizagem. (2006, p.87)

Assim, voltando-nos novamente para o fato de como as crenças sobre a aprendizagem estão ligadas à noção de a autonomia, voltamos também para nossas questões iniciais. Para os alunos-instrutores/sujeitos de nossa pesquisa, as crenças, muitas vezes, favorizam a aprendizagem quando são superadas as dificuldades impostas pelo contexto e este passa a ser o centralizador de seus esforços. Assim, ao elaborar estratégias que interajam favoravelmente no contexto, o aluno-instrutor pode progredir e fazer progredir, pode ser autônomo e gerar autonomia, pode construir uma nova identidade, fluida, sem perder seu ponto de partida. Dessa forma, o aprendiz pode ir em direção a uma noção mais ampla de autonomia, elaborada por Freire (1996), que a concebe como possibilidade de um aprendiz que vá além das orientações do que se deve ou não fazer para aprender, mas que seja verdadeiros construtores de seu próprio conhecimento.

\section{REFERÊNCIAS}

ALMEIDA FILHO, J. C. P. Dimensões comunicativas no ensino de línguas. Campinas: Pontes, 1993.

2005.

(org.). O professor de língua estrangeira em formação. $2^{\mathrm{a}}$ ed. Campinas: Pontes,

BARCELOS, A. M. F. "Crenças sobre aprendizagem de línguas, linguística aplicada e ensino de línguas". In: Linguagem \& ensino. v. 7, n.1, p. 123-156, 2004.

. "Reflexões acerca da mudança de crenças sobre ensino e aprendizagem de línguas". In: Revista Brasileira de Linguística Aplicada, v. 7, n. 2, p. 109-138, 2007.

"Narrativas, crenças e experiência de aprender inglês". Revista Linguagem \& Ensino, v. 9 , n. 2 , p. $145-175,2012$.

"Metodologia de Pesquisa das Crenças sobre Aprendizagem de Línguas: Estado da Arte”. In: Revista Brasileira de Linguística Aplicada, v. 1, n. 1, p. 71-92, 2001.

BROWN, D. Teaching by Principles. New York: Pearson Education, 2001. 
CARRARO, C; NATEL, T. "As crenças de professores brasileiros de espanhol sobre o papel da gramática”. In: SILVA, K.P. (org.) Crenças, discursos e linguagem. Campinas: Pontes, 2011.

FÉLIX, A. "Crenças de duas professoras de uma escola pública sobre o processo de aprender língua estrangeira". In: ALMEIDA FILHO, J.C. de (org.). O professor de língua estrangeira em formação. $2^{\mathrm{a}}$ ed. Campinas: Pontes, 2005.

FREIRE, P. A pedagogia da autonomia. São Paulo: Paz e. Terra, 1996.

HOLEC, H. “Qu'est-ce que c'est apprendre?”. In: Mélanges pédagogiques. v. 1990, p. 75-87, 1990.

HORWITZ, Elaine K. "Cultural and situational influences on foreign language learners' beliefs about language learning: A review of BALLI studies". In: System, v. 27, n. 4, p. 557$576,1999$.

KAJALA, P. "Student Beliefs (or metacognitive knowledge) about SLA reconsidered". In: International journal of applied linguistics. v. 5, n. 2, p.191-204, 1995.

KUMARAVADIVELU, B. "Language-learning tasks: teacher's intention and learner's interpretation”. In: ELT jornal. Oxford, v. 45, n.2, p. 98-107, 1991.

KUDIESS, E. "As Crenças e os Sistemas de Crenças do Professor de Inglês sobre o Ensino e a Aprendizagem da Língua Estrangeira no Sul do Brasil: Sistemas, Origens e Mudanças". In: Linguagem e ensino. Pelotas. v. 8, n.2, p. 39-96, 2005.

PIRES, Tássia Lutiana Severo; DOS SANTOS LIMA, Marília. "Narrativas e crenças de alunos universitários de língua inglesa: o processo de ensino-aprendizagem visto pelo olhar dos aprendizes”. Domínios de Lingu@gem, v. 8, n. 1, p. 295-315, 2014.

MAKIYAMA, S. Teacher and students' beliefs on learning strategies in a EFL classroom. 2008. Dissertação (Mestrado em Linguística) - Faculdade de Letras, Universidade Federal de Alagoas, Maceió, 2008.

Ensino de inglês na escola pública: o básico do básico? Maceió: Edufal, 2015. MONTI, Fabiana Gonçalves et al. Formação de professores de Lingua Inglesa: crenças docentes e discentes acerca do Bom Professor. Dissertação (Mestrado em Ciências Humanas) - Universidade do Oeste Paulista, Presidente Prudente, 2012.

OXFORD, R. Language Learning Strategies: What every teacher should know. New York: Harper Collins, 1990.

PAIVA, V.L.M.O. “Autonomia e complexidade”. In: Linguagem \& Ensino, Vol. 9, No. 1, 2006, p.77-127.

"As habilidades orais nas narrativas de aprendizagem". In: Trabalhos em Linguística Aplicada. v. 46, n.2.p.165-179, 2007. 
PAJARES, M. Frank. "Teachers' beliefs and educational research: Cleaning up a messy construct". Review of educational research, v. 62, n. 3, p. 307-332, 1992.

PECHEUX, M. Semântica e discurso: uma crítica à afirmação do óbvio. 4. ed. Campinas: Pontes, 2009.

REVUZ, C. "A língua estrangeira entre o desejo de um outro lugar e o risco de exílio". In SIGNORINI, I. (org.) Lingua(gem) e identidade: elementos para uma discussão no campo aplicado. Campinas: Mercado de Letras, 2006. p. 213-230.

SERRANI-INFANTE, S. Identidade e segundas línguas: as identificações no discurso. IN: SIGNORINI, I. Língua(gem) e identidade. Campinas: Mercado de Letras, 2006, p. 231-261.

SILVA, K.P. (org.) Crenças, discursos e linguagem. Campinas: Pontes, 2011.

UNIÃO EUROPEIA. Quadro europeu comum de referência para as línguas: aprendizagem, ensino, avaliação. 2001.

VYGOTSKY, L. S. Pensamento e linguagem. São Paulo: Martins Fontes, 2008.

WOODS, D. Teacher cognition in language teaching: Beliefs, decision-making, and classroom practice. Cambridge: Cambridge University Press, 1996.

WOODWARD, Kathryn. "Identidade e diferença: uma introdução teórica e conceitual”. In: SILVA, Tomaz Tadeu da. Identidade e Diferença. Trad.: Tomaz Tadeu da Silva. $8^{\mathrm{a}} \mathrm{ed}$. Petrópolis - RJ: Vozes, 2000. p. 7-71.

\section{Anexo \\ QUESTIONÁRIO}

1) Abaixo estão alguns enunciados que se referem as diferentes técnicas que estudantes de língua estrangeira podem usar para auxiliar seu aprendizado. Para cada enunciado, indique o tão quanto você usa da estratégia descrita usando os números de 1 a 5 de acordo com a escala abaixo. Por exemplo, se você utiliza a técnica muito frequentemente, marque 4; se você sempre usa a técnica marque 5 .

\begin{tabular}{|c|c|c|c|c|}
\hline 1 & 2 & 3 & 4 & 5 \\
\hline Nunca uso isso & $\begin{array}{c}\text { Utilizo um } \\
\text { pouco }\end{array}$ & Algumas vezes & $\begin{array}{c}\text { Muito } \\
\text { frequentemente }\end{array}$ & Sempre a uso \\
\hline
\end{tabular}

1. Eu planejo meu cronograma para que eu tenha tempo suficiente para estudar língua estrangeira.

2. Eu procuro por pessoas com quem eu possa falar em língua estrangeira.

3. Eu busco por oportunidades para ler o máximo possível em língua estrangeira.

4. Eu tenho objetivos claros para melhorar em língua estrangeira.

5. Eu penso em meu progresso ao aprender língua estrangeira.

6. Eu tento relaxar sempre que sinto medo de usar língua estrangeira. 


\begin{tabular}{|l|l|}
\hline $\begin{array}{l}\text { 7. Eu me encorajo a falar língua estrangeira mesmo quando eu sinto medo de } \\
\text { cometer um erro. }\end{array}$ & \\
\hline $\begin{array}{l}\text { 8. Eu dou uma recompensa ou agrado a mim mesmo quando eu vou bem em } \\
\text { língua estrangeira. }\end{array}$ & $\begin{array}{l}\text { 9. Eu noto se estou tenso ou nervoso quando eu estou estudando ou usando língua } \\
\text { estrangeira. }\end{array}$ \\
\hline 10. Eu escrevo meus sentimentos em uma linguagem de aprendizado diariamente. \\
\hline $\begin{array}{l}\text { 11. Eu falo com alguém sobre como eu me sinto quando estou aprendendo língua } \\
\text { estrangeira. }\end{array}$ \\
\hline $\begin{array}{l}\text { 12. Se eu não entendo algo em língua estrangeira, eu peço à outra pessoa para falar } \\
\text { devagar ou repetir. }\end{array}$ \\
\hline 13. Eu peço à falantes de língua estrangeira para me corrigir quando eu falo. \\
\hline 14. Eu pratico língua estrangeira com outros estudantes. \\
\hline 15. Eu peço ajuda a falantes de língua estrangeira. \\
\hline 16. Eu faço perguntas em língua estrangeira. \\
\hline 17. Eu tento aprender sobre a cultura dos falantes de língua estrangeira. \\
\hline
\end{tabular}

2) Classifique a ordem de importância de um a cinco (1 - o mais importante; 5 - o menos importante) do que você considera mais importante quando alguém lhe pede ajuda com o aprendizado em língua estrangeira.

( ) a forma que você aborda

( ) seu entendimento do assunto antes do auxílio

( ) o conhecimento prévio desse indivíduo

( ) entendimento do assunto pelo indivíduo após o auxílio

( ) a identidade cultural do indivíduo

3) Quais atividades você mais gosta?

( ) tradução/ ( ) interpretação de textos/ ( )leitura em voz alta/ ( )diálogo/( )teatro/ ( )filmes/ ( )gramática/ ( ) música/ ( ) brincadeiras/ ( )produção de texto/ ( ) explicação da matéria/ ( ) provas/ ( )exercícios do livro/ ( )apresentação de trabalhos.

4) Qual tipo de atividade faz você ter receio?

( ) tradução/ ( ) interpretação de textos/ ( )leitura em voz alta/ ( )diálogo/( )teatro/ ( )filmes/ ( )gramática/ ( ) música/ ( ) brincadeiras/ ( )produção de texto/ ( ) explicação da matéria/ ( ) provas/ ( )exercícios do livro/ ( )apresentação de trabalhos.

5) você acha que quando o professor trabalha assuntos e fala sobre ambientes que o aluno conhece bem, isso facilita o aprendizado do aluno?

( ) $\operatorname{sim}($ ) não

6) você tem objetivos claros do porquê estuda língua estrangeira?

( ) $\operatorname{sim}($ ) não

7) quais níveis você pretende alcançar com esta língua estrangeira?

( ) Iniciante - quero só ter alguma noção dela, não me interessa o aprofundamento.

( ) intermediário - quero poder ter certo domínio, mas não pretendo fazer desta língua a minha principal língua estrangeira.

( ) avançado - quero conhecer ao máximo os mecanismos desta língua e para isso me dedico muito.

8) Para alcançar o nível desejado, você estuda também em casa? 
( ) $\operatorname{sim}($ ) não

( ) não tanto quanto gostaria

9) Se você respondeu afirmativamente a questão anterior, quais recursos você utiliza ao estudar em casa?

( ) material indicado ou enviado pelo professor/ ( ) faço os exercícios do caderno de atividade/ ( ) busco por minha conta sites na internet/ ( ) busco por minha conta livros de fonética, gramática, vocabulário/

10) Ainda se você respondeu afirmativamente à questão 8, quando você estuda sozinho, consegue ter noção se está progredindo ou não naquilo que se propôs a estudar?

( ) $\operatorname{sim}($ ) não

11) Classifique em ordem de importância de um a cinco (1 - o mais importante; 5 - o menos importante) as estratégias de ensino/aprendizagem em LE

( ) dedicar várias horas de estudo

( ) conhecer bem seus objetivos

( ) saber se autoavaliar e buscar melhorar

( ) fazer uma imersão em um país falante de sua língua-alvo

( ) seguir um bom método didático

12) Qual dessas é a melhor forma de aprender sobre os aspectos culturais?

( ) dedicar várias horas de estudo

( ) conhecer bem seus objetivos

( ) saber se autoavaliar e buscar melhorar

( ) fazer uma imersão em um país falante de sua língua-alvo

( ) seguir um bom método didático

( ) conhecer as expressões artísticas nessa língua. 